\title{
A new co-culture method for identifying synaptic adhesion molecules involved in synapse formation
}

\author{
Wei Jiang ${ }^{1,2}$, Jihong Gong ${ }^{1,3}$, Yi Rong ${ }^{1}$, Xiaofei Yang ${ }^{1 凶}$ \\ ${ }^{1}$ Key Laboratory of Cognitive Science, Hubei Key Laboratory of Medical Information Analysis and Tumor Diagnosis \\ \& Treatment, Laboratory of Membrane Ion Channels and Medicine, College of Biomedical Engineering, South- \\ Central University for Nationalities, Wuhan 430074, China \\ 2 College of Biology, Hunan University, Changsha 410082, China \\ ${ }^{3}$ Key Laboratory of Molecular Biophysics of Ministry of Education, College of Life Science and Technology, Huazhong \\ University of Science and Technology, Wuhan 430074, China
}

Received: 10 May 2018 / Accepted: 26 October 2018 / Published online: 12 March 2019

\begin{abstract}
The proper formation of synapses is essential for brain function. Synaptic cell adhesion molecules (CAMs) are thought to play essential roles in the initiation of the synapse formation process. The artificial synapse formation assay, in which non-neuronal cells and neurons are co-cultured, has been shown to be a powerful system for screening CAMs. However, controlling a large number of cell pools in co-culture is complicated, creating a potential barrier for high-throughput screening. This protocol describes a new co-culture method in which cDNA plasmid is transfected into human embryonic kidney $293 \mathrm{~T}$ cells using polyetherimide $24 \mathrm{~h}$ after cells were mixed with neurons, and immunostaining and confocal imaging are employed for analyzing synaptogenesis. This optimized method is simpler and easier to perform than the traditional method for the examination of the synaptogenic activities of individual cell-surface proteins in isolation, and provides an unbiased screening platform for synaptogenic proteins.
\end{abstract}

Keywords Co-culture assay, Synapse formation, Synaptic cell adhesion molecules, Polyetherimide

\section{INTRODUCTION}

The brain is characterized by an enormous degree of complexity and diversity of neural networks, making it one of the most complicated organs, and plays essential roles in regulating body and mind, maintaining thinking and other important physiology actions. Chemical synapses are the elementary structure of neural networks and allow a neuron to communicate with other neurons through the release of neurotransmitters. The proper formation of a synapse is essential to the construction of neural circuits and cognitive functions, and alterations in this process lead to many neurological disorders, such as autism spectrum disorders and

$\bowtie$ Correspondence: sunlittlefly@hotmail.com (X. Yang) mental retardation (Boda et al. 2010; McAllister 2007; Sudhof 2008; Zhang et al. 2009). Major efforts have been made to define the molecular composition of synapses (Harris and Weinberg 2012; Pereda 2014; Sudhof 2004; Sudhof and Malenka 2008), and now, our understanding of how synapses function in presynaptic terminals and postsynaptic spines has greatly expanded. However, much less is known about the molecular mechanism that determines the targeted initiation of synapse formation, partly due to the enormous variety of synapses in the brain.

Synaptic cell adhesion molecules (CAMs) were originally assumed to enable cell-cell recognition and play an important role in initiating the formation of synapses through trans-synaptic interactions (Sanes and Yamagata 2009; Yang et al. 2014). The artificial synapse 
formation (ASF) assay has been shown to be an efficient system for screening CAMs, having been tested by several families of known CAMs, including neurexins (Graf et al. 2004) and neuroligins (Varoqueaux et al. 2006), Synaptic cell adhesion molecules (SynCAMs) (Biederer et al. 2002), ephrinBs and EphBs (Aoto et al. 2007; Kayser et al. 2006), NGLs/LRRC4 s (Kim et al. 2006), LRRTMs (Linhoff et al. 2009), and PTPRO (Jiang et al. 2017). However, evidence from analyses of most known CAM knockout (KO) mice indicates that these CAMs mediate synapse maturation and synaptic plasticity rather than the initiation of synapse formation (Chubykin et al. 2007; Missler et al. 2003). Thus, the complete molecular mechanism for synapse formation remains elusive. Although the ASF assay is powerful for identifying CAMs, it is still inconvenient for highthroughput screening because non-neuronal cells have to be transfected and digested before they are mixed with neurons. Here, we describe a new co-culture method that is easier for screening CAMs.

\section{MATERIALS AND EQUIPMENT}

\section{Materials and reagents}

Mouse hippocampal neurons obtained using animal procedures performed in accordance with animal use rules and the requisite approvals of animal use committees of South-Central University for Nationalities, sterile cover glasses, HEK293T cells, Dulbecco's modified Eagle's medium (Gibco, 12800-017), 0.25\% trypsin-EDTA phenol red (Gibco, 25200056), 0.05\% trypsin-EDTA (Gibco, 25300054), DNA purification kits, Top10 strain, ampicillin plates, tissue culture flasks, 6and 24-well tissue culture plates, and polyethylenimine (Polysciences, 24765-2).

\section{Equipment}

Laminar flow hood, tissue culture hood, cell culture incubator $\left(37{ }^{\circ} \mathrm{C}, 100 \%\right.$ humidity, $\left.5 \% \mathrm{CO}_{2}\right)$, hemocytometer, inverted epifluorescence microscope, a confocal microscope with a standard set of lasers and suitable image analysis software (Nikon N2 Confocal).

\section{REAGENT SETUP}

\section{Dissection solution}

HEPES (1 mmol/L; Sigma, $\mathrm{H} 4034)$ and $\mathrm{NaHCO}_{3}$ (4 mmol/L; Sigma, S8875) prepared in Hank's balanced salt solution (Sigma, H2387) with pH adjusted to 7.3 and 7.4 and osmotic pressure adjusted to 300 to $320 \mathrm{mOsm} / \mathrm{kg}$, filtered through a $0.22-\mu \mathrm{m}$ filter, and stored at $4{ }^{\circ} \mathrm{C}$ away from light for up to 1 month.

\section{Stop digestion solution}

FBS $(5 \%(v / v)$; Invitrogen, 10099141; qualified, heatinactivated), HEPES ( $1 \mathrm{mmol} / \mathrm{L}$; Sigma, H4034) and $\mathrm{NaHCO}_{3}$ (4 mmol/L; Sigma, S8875) prepared in Hank's balanced salt solution (Sigma, H2387) with $\mathrm{pH}$ adjusted to 7.3 to 7.4 and osmotic pressure adjusted to 300 to $320 \mathrm{mOsm} / \mathrm{kg}$, filtered through a $0.22-\mu \mathrm{m}$ filter, separated into $40 \mathrm{~mL}$ aliquots, and stored at $-20{ }^{\circ} \mathrm{C}$ for up to 2 months.

\section{Plating medium}

Glucose $\left(0.5 \%(w / v)\right.$; Sigma, G6152), $\mathrm{NaHCO}_{3}(2.2 \%$ $(w / v)$; Sigma, S8875), FBS $(10 \%(v / v)$; Invitrogen, 10099141; qualified, heat-inactivated), transferrin (0.1\% (w/v); Calbiochem, 616420), and insulin $(0.025 \%$ $(w / v)$; Sigma, I6634), prepared in MEM (Gibco, 61100-061) with pH adjusted to 7.3 to 7.4 and osmotic pressure adjusted to 300 to $320 \mathrm{mOsm} / \mathrm{kg}$, filtered through a $0.22-\mu \mathrm{m}$ filter, separated into $40 \mathrm{~mL}$ aliquots, and stored at $-20^{\circ} \mathrm{C}$ for up to 2 months.

\section{Neuronal growth medium}

B-27 supplement $(0.1 \%(w / v)$; Gibco, 17504-010), glucose $\left(0.5 \%(w / v)\right.$; Sigma, G6152), $\mathrm{NaHCO}_{3}(2.2 \%(w / v)$; Sigma, S8875), FBS (5\% $(v / v)$; Invitrogen, 10099141; qualified, heat-inactivated), transferrin $(0.1 \%(w / v)$; Calbiochem, 616420), and insulin $(0.025 \%(w / v)$; Sigma, I6634), prepared in MEM (Gibco, 61100-061).

\section{Neuronal growth medium plus 4-AraC}

Neuronal medium adjusted to $4 \mu \mathrm{mol} / \mathrm{L}$ arabinocytidine hydrochloride (Ara-C; Sigma, C6645).

\section{PROCEDURE}

\section{Coverslip preparation}

(1) Place 300 coverslips in a $50 \mathrm{~mL}$ tube. Wash once with $30 \mathrm{~mL}$ xylene, twice with $30 \mathrm{~mL}$ acetone, once with $30 \mathrm{~mL} \mathrm{100 \%}$ ethanol, once with $30 \mathrm{~mL}$ $70 \%$ ethanol, and at least three times with $30 \mathrm{~mL}$ $\mathrm{ddH}_{2} \mathrm{O}$ (Rotate at least $30 \mathrm{~min}$ for each step at room temperature). 
(2) Autoclave the coverslips in $\mathrm{ddH}_{2} \mathrm{O}$. Place all the coverslips in a new $50 \mathrm{~mL}$ tube.

(3) Rotate the coverslips in $30 \mathrm{~mL} 0.1 \mathrm{mg} / \mathrm{mL}$ poly-Llysine overnight at $4{ }^{\circ} \mathrm{C}$ to coat the coverslips and then store at $4{ }^{\circ} \mathrm{C}$.

(4) Place each $12 \mathrm{~mm}$ coverslip in individual plate wells and wash the coverslips three times with

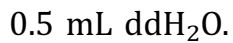

\section{Dissociated hippocampal culture preparation}

(5) Autoclave anatomy instruments before the experiment. To prepare the enzyme solution, incubate $0.25 \%$ trypsin + EDTA for approximately $30 \mathrm{~min}$ before use. Warm the plating medium before use (approximately $30 \mathrm{~min}$ ).

(6) Dissociate mouse hippocampal neurons on the day of birth (P0) to prepare mixed neuron/glia cultures. Dissect the hippocampus in a tissue culture hood, place the hippocampal tissue into a $15 \mathrm{~mL}$ tube (with HBS freshly from $4{ }^{\circ} \mathrm{C}$ ) with dissection solution on ice and allow the mixture to settle on ice.

(7) Wash these hippocampal preparations three times with ice-cold dissection solution and incubate with $1 \mathrm{~mL} 0.25 \%$ trypsin + EDTA for $12 \mathrm{~min}$ in the incubator.

(8) Remove the enzyme solution, wash the tissue with HBS $+10 \%$ FBS three times, and place the tissue into $1.5 \mathrm{~mL}$ plating medium. Break down the tissue by trituration (using $800 \mu \mathrm{L}$ pipette tip 15-20 times).

(9) Centrifuge cells at $800 \mathrm{~g}$ for $5 \mathrm{~min}$ and resuspend them in $400 \mu \mathrm{L}$ plating medium. Count cells and add plating medium to adjust the cell density to 80,000 cells $/ 50 \mu \mathrm{L}$. Add $50 \mu \mathrm{L}$ of cell-containing medium per well and place the plate in the cell culture incubator (Day 0).

(10) Thirty minutes later, add $1 \mathrm{~mL}$ of plating medium per well and place the plate in the cell culture incubator.

(11) On day 1 , remove $500 \mu \mathrm{L}$ medium from each well and replace it with $600 \mu \mathrm{L}$ growth medium $(0 \mu \mathrm{mol} / \mathrm{L}$ Ara-C).

(12) On day 4, remove $500 \mu \mathrm{L}$ medium from each well and replace it with $600 \mu \mathrm{L}$ growth medium $(4 \mu \mathrm{mol} / \mathrm{L}$ Ara-C).

(13) On day 9 , remove $500 \mu \mathrm{L}$ medium from each well and replace it with $600 \mu \mathrm{L}$ growth medium (4 $\mu \mathrm{mol} / \mathrm{L}$ Ara-C).

[CRITICAL STEP] Medium change is performed by replacing only half of the old medium with fresh medium. Changing the medium completely will result in neuronal cell death.

\section{HEK293T cell-hippocampal neuron mixed culture}

(14) On day in vitro (DIV) 7 of neuronal culture, place HEK293T cells atop the dissociated hippocampal neurons.

[CRITICAL STEP] Resuspend HEK293T cells in growth medium $(2 \mu \mathrm{mol} / \mathrm{L}$ Ara-C).

\section{HEK293T cell transfection}

(15) One day later, on DIV 8 of the mixed culture, transfect the mixed cells to express the membrane protein to be tested for its role in synapse induction. Polyetherimide (PEI) transfects cDNA plasmids into the HEK293T cells specially but not neurons in HEK293T-neuron mixed culture.

\section{Synapse induction analysis by synaptic marker immunostaining}

(16) Perform analysis $48 \mathrm{~h}$ after the transfection of the HEK293T-neuron mixed cultures. Fix and stain mixed cultures with synapsin (synaptic marker).

(17) Observe the induction of presynaptic specializations mainly along the cell boundary and atop these co-cultured HEK293T cells by confocal microscopy imaging.

\section{RESULTS}

The efficacy of the optimized co-culture assay to determine the synaptogenesis activity of CAMs by transfection of hippocampal neurons and HEK293T mixed cells was examined. The HEK293T cells were digested and seeded atop dissociated hippocampal neurons on DIV 7. After $24 \mathrm{~h}$, both neurons and HEK293T cells were transfected with FUGW-GFP together with PCMV5-neuroligin 2 (NL2) plasmids by PEI methods, differing from the most commonly used co-culture assay (Fig. 1A). Because cultured neurons failed to be transfected by PEI, only HEK293T cells successfully expressed GFP and NL2 protein. The coculture activity of the optimized co-culture assay was measured by immunostaining and confocal microscopy (Fig. 1B). We transfected NL2 in HEK 293T cells for $24 \mathrm{~h}$ and then co-cultured the HEK293T cells with hippocampal neurons on DIV 9 for an 
A

Express clone in HEK293T cells (Day 0)

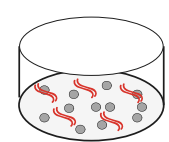

B

Plate HEK293T cells with Hippo. neurons (DIV 7) (Day 0)

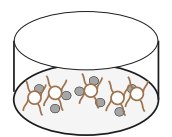

\section{Co-culture assay}

Plate HEK293T cells with Hippo. neurons (DIV 9) (Day 1-3) HEK293T cells (Day 1)
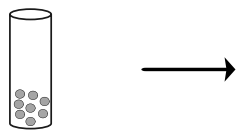

IHC analysis with synapsin $\mathrm{Ab}$.

(Day 3)

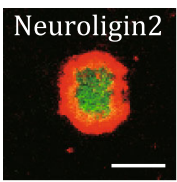

Optimized co-culture assay

Express clone in HEK293T cells (Day 1)
IHC analysis with synapsin $\mathrm{Ab}$. (Day 3)

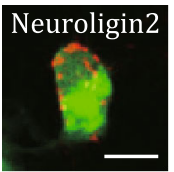

\begin{tabular}{|ll|}
\hline P Plasmids $\quad$ HEK293T Neuron \\
\hline
\end{tabular}

Fig. 1 Schematic illustrating the procedures of the original and optimized co-culture assays. A Schematic drawing of the original coculture assay of hippocampal neurons mixed with HEK293T cells expressing target DNA. B Schematic drawing of the optimized co-culture assay of hippocampal neurons mixed with HEK293T cells expressing target DNA. Scale bars, $20 \mu \mathrm{m}$

additional $48 \mathrm{~h}$ as a positive control, and an empty pCMV5 vector was used as the negative control. (Fig. 2A). Synapse staining with an antibody against synapsin was performed, and a program based on the co-culture index measurement (Jiang et al. 2017) was executed to identify positive cells (Fig. 2B). In our optimized co-culture assay, the activity of
HEK293T cells expressing GFP and NL2 was significantly greater than that in the control in which HEK293T cells expressed FUGW-GFP and the PCMV-5 vector (Fig. 3A, B). The data showed that the optimized co-culture system achieved similar synapse formation as the system using pre-existing protocols for co-culture assay employing NL2.
A

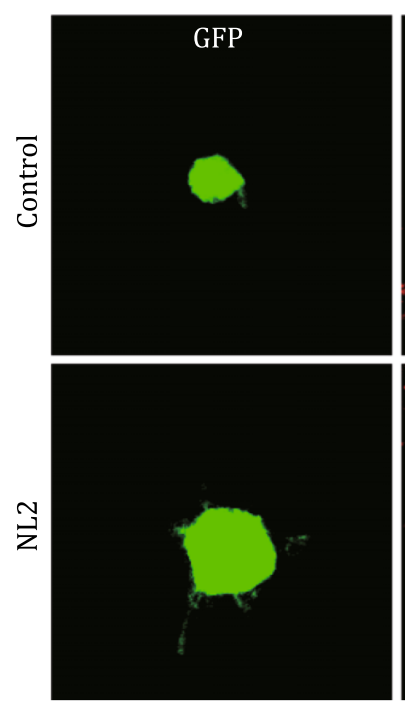

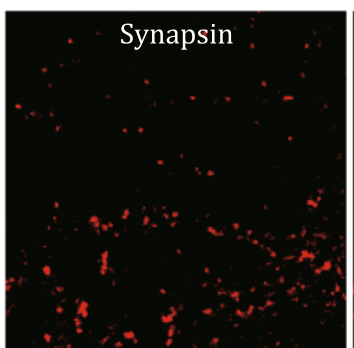

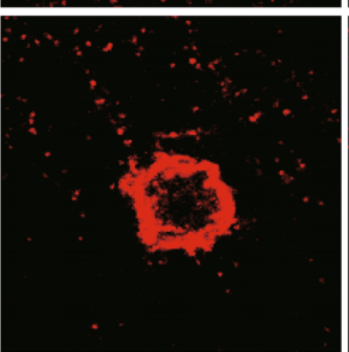

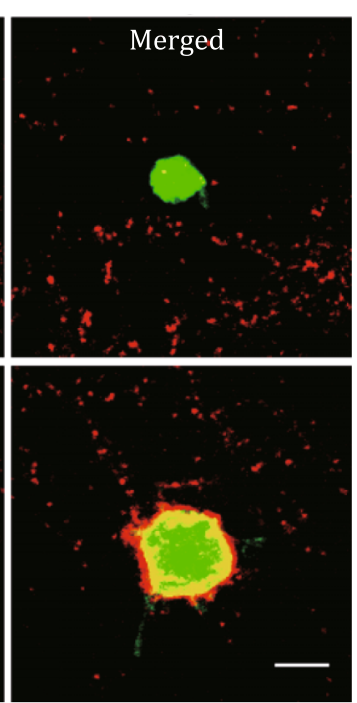

B

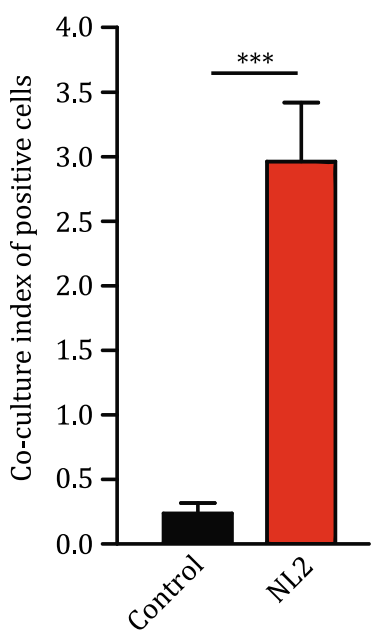

Fig. 2 NL2 expression in HEK293T cells induces synapse formation in a co-culture assay. A Representative images of hippocampal neurons co-cultured with HEK293T cells expressing FUGW-GFP together with PCMV5 vector (control) or PCMV5-NL2 (NL2) stained by synapsin. Scale bars, $20 \mu \mathrm{m}$. B Summary graph of the co-culture index of cells from the control or pCMV5-NL2-transfected HEK293T cells co-cultured with hippocampal neurons. Summary graph shows the mean \pm SEM; statistical comparison was made with Student's $t$-test $\left({ }^{* * *} P<0.001\right)$ 
A
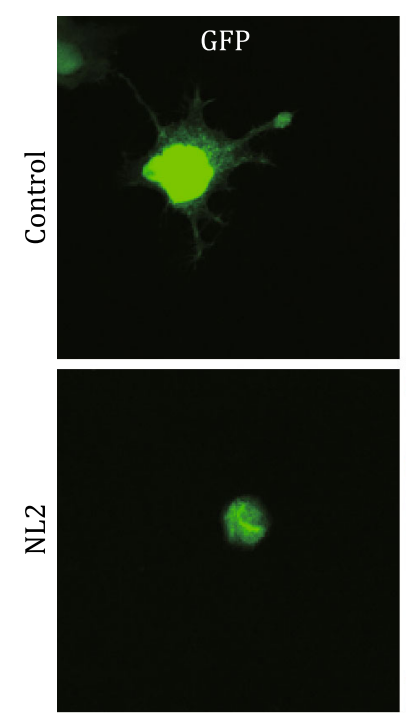

Optimized co-culture assay
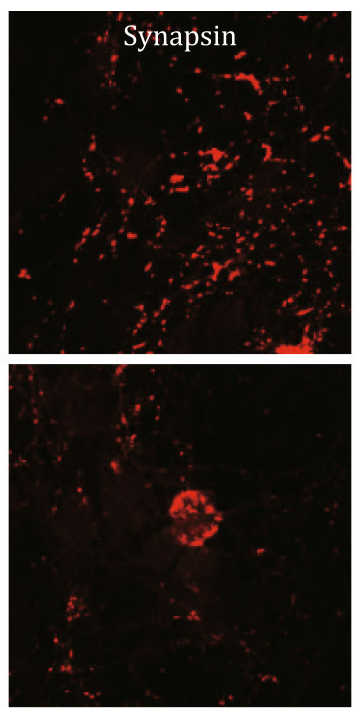
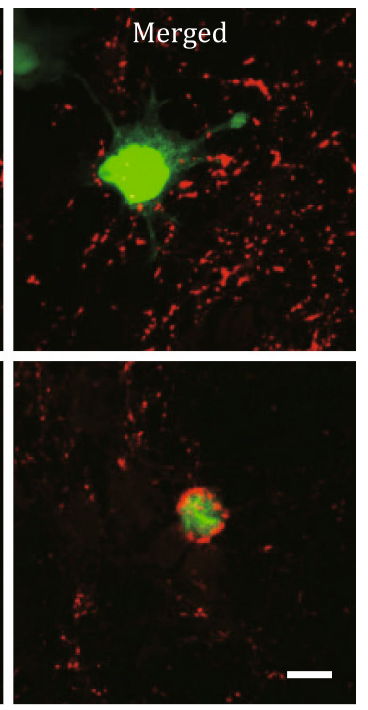

B

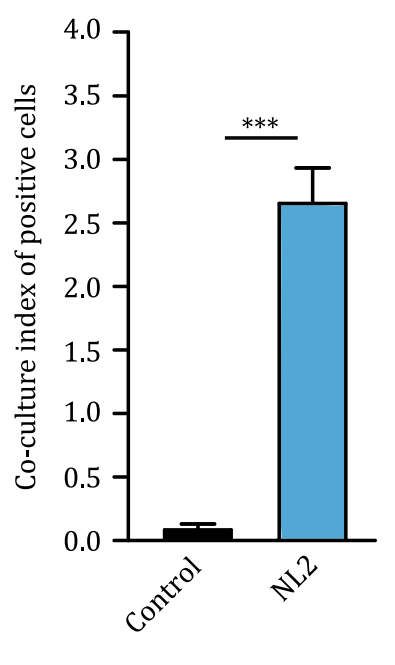

Fig. 3 NL2 expression in HEK293T cells induces synapse formation in the optimized co-culture assay. A Representative fluorescence images of hippocampal neurons co-cultured with HEK293T cells expressing FUGW-GFP together with PCMV5 vector (control) or PCMV5NL2 (NL2) stained by synapsin in the optimized co-culture assay. Scale bars, $20 \mu \mathrm{m}$. B Summary graph of the co-culture index of cells from the control or pCMV5-NL2-transfected HEK293T cells co-cultured with hippocampal neurons. Summary graph shows the mean \pm SEM; statistical comparison was made with Student's $t$-test $(* * * P<0.001)$

Next, to check the high-throughput CAM screening ability of the optimized co-culture assay in synapse formation, NL1-4 and PTPRO were employed as a test set of synaptic adhesion molecules. Transfected HEK 293T cells were co-cultured with hippocampal neurons by co-culture assay or optimized co-culture assay (Fig. 4A, B). Then, the co-culture index and the required time and tips, including subculture of HEK293T cells, transfection and co-culture steps of the two assays, were quantified. Compared with the co-culture assay, the optimized co-culture assay achieved similar co-culture activity based on the co-culture index measurement (Fig. 4C, D). However, the time and tips required for the optimized co-culture assay were significantly decreased (Fig. 4E). Therefore, the optimized co-culture assay represents a new method for highthroughput CAM screening in synapse formation. Taken together, the data obtained using this assay have implications for synapse formation, and this optimized assay can be used not only for the identification of novel synaptogenic molecules but also as a more convenient method for high-throughput CAM screening with an abbreviated operating procedure.

\section{DISCUSSION}

The identification of CAMs involved in synapse formation is critical for understanding synaptogenesis and neural circuits. Although other identification methods involving single-cell RNA sequencing (RNAseq) or highresolution liquid chromatography-tandem mass spectrometry (LC-MS/MS) have been reported (Foldy et al. 2016; Frese et al. 2017), co-culture assays are still the most widely used methods to identify CAMs; however, the complicated control of high-throughput screening may represent a barrier in the screening process. Here, the data demonstrated that this optimized co-culture assay can identify CAMs through the transfection of NL2 plasmids into HEK293T cells by PEI after HEK293Tneurons were mixed (Fig. 3). Furthermore, using NL1-4 and PTPRO plasmids as a test set of CAMs for screening, the optimized co-culture assay achieved similar co-culture activity based on co-culture index measurement. Moreover, the data showed that the time and tips required for the optimized co-culture assay were significantly decreased (Fig. 4).

Several alternative methods bypassing the co-culture assay have been reported to identify CAMs (Foldy et al. 2016; Frese et al. 2017). Single-cell RNAseq was used to identify CAMs; neurons were first electrophysiologically characterized, and their transcriptome was subsequently analyzed by aspiration of the cytosol followed by single-cell RNAseq. This method has the advantage of analyzing gene expression in specific cell types in a defined circuit. LC-MS/MS using a systematic and indepth proteome analysis of cultured hippocampal neurons, which can establish a quantitative map of the 
A
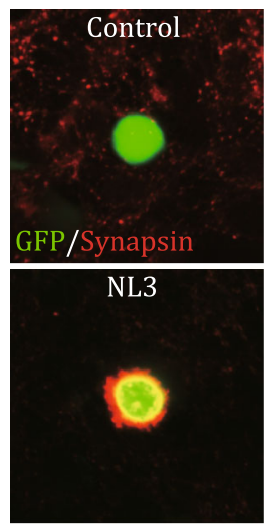

Co-culture assay (CA)
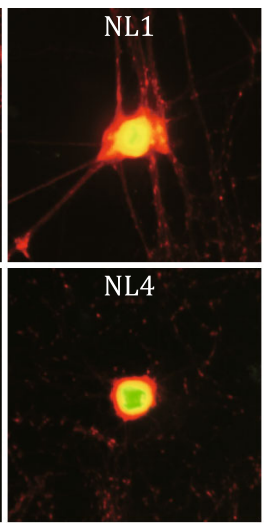

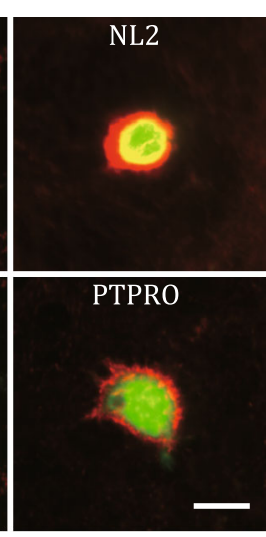

B

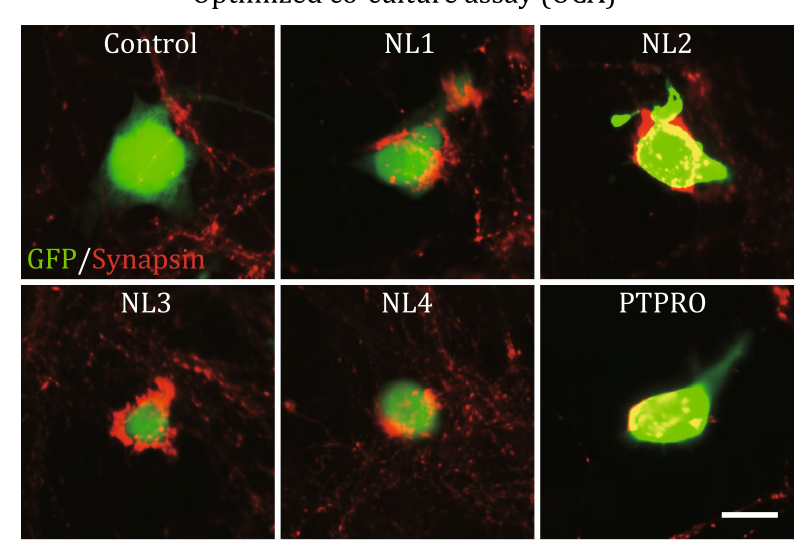

C

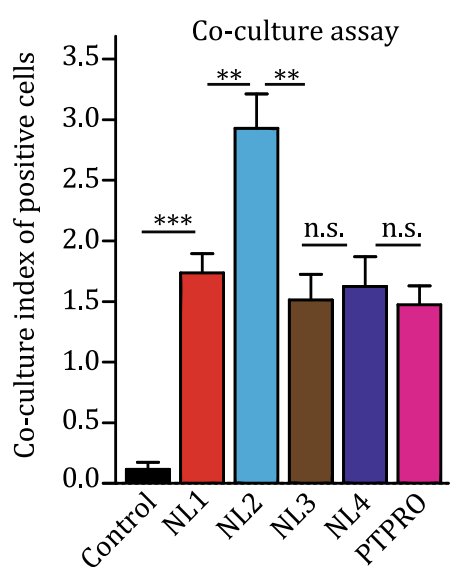

D

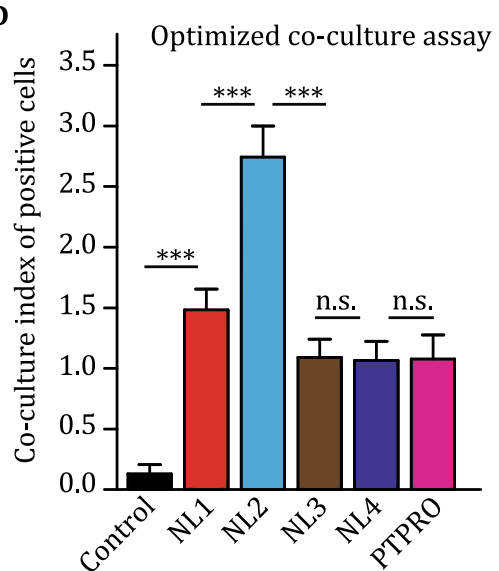

E

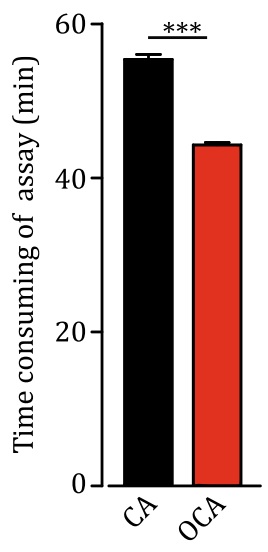

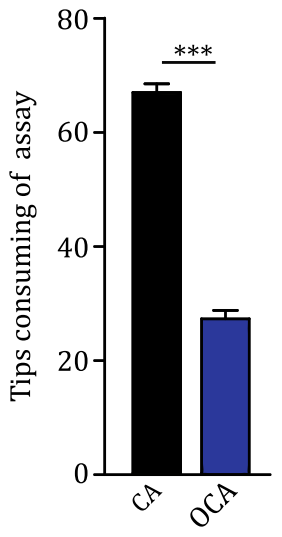

Fig. 4 Co-culture assay and optimized co-culture assay for synaptic adhesion molecule screening. A, B Representative image of hippocampal neurons co-cultured with HEK293T cells expressing a test set of synaptic adhesion molecules using the co-culture assay (A) or optimized co-culture assay (B). C, D Summary graphs of the co-culture index of cells from the control, NL1, NL2, NL3, NL4 or PTPRO-transfected HEK293T cells co-cultured with hippocampal neurons using the co-culture assay (C) or optimized co-culture assay (D). E The time (left) and tips (right) required for the co-culture assay compared with those for the optimized co-culture system. Scale bars, $20 \mu \mathrm{m}$; scale bars apply to all panels in a set. All summary graphs show the mean \pm SEM; statistical comparisons were made with Student's $t$-test ${ }^{* *} P<0.01,{ }^{* * *} P<0.001 ;$ n.s. not significant)

neuron-specific proteome during developmental stages, was also reported to identify CAMs. Overexpression of CAMs in cultured neurons is another simple and efficient way to identify specific CAMs or CAM families (Kim et al. 2006). Recently, a novel fluorescenceactivated synaptosome sorting (FASS) method with substantially improved conventional synaptosome enrichment protocols enabling high-resolution biochemical analyses of specific synapse subpopulations was reported (Biesemann et al. 2014). Employing primary cultured cells from knock-in mice with fluorescent glutamatergic synapses together with this optimized coculture assay could be a simpler and more powerful system to identify special excitatory postsynaptic CAMs. This method is relatively time-effective and especially suitable for handling a large variety of CAM screens.
Acknowledgements This work was supported by the National Natural Science Foundation of China (31670850).

\section{Compliance with Ethical Standards}

Conflict of interest All the authors declare that they have no conflict of interest.

Animal rights and informed consent All institutional and national guidelines for the care and use of laboratory animals were followed. All experimental procedures involving mice were performed under a protocol approved by the animal research ethics committee of South-Central University for Nationalities.

Open Access This article is distributed under the terms of the Creative Commons Attribution 4.0 International License (http:// creativecommons.org/licenses/by/4.0/), which permits unrestricted use, distribution, and reproduction in any medium, provided you give appropriate credit to the original author(s) and the source, provide a link to the Creative Commons license, and indicate if changes were made. 


\section{References}

Aoto J, Ting P, Maghsoodi B, Xu N, Henkemeyer M, Chen L (2007) Postsynaptic ephrinB3 promotes shaft glutamatergic synapse formation. J Neurosci 27:7508-7519

Biederer T, Sara Y, Mozhayeva M, Atasoy D, Liu X, Kavalali ET, Sudhof TC (2002) SynCAM, a synaptic adhesion molecule that drives synapse assembly. Science 297:1525-1531

Biesemann C, Gronborg M, Luquet E, Wichert SP, Bernard V, Bungers SR, Cooper B, Varoqueaux F, Li L, Byrne JA, Urlaub H, Jahn O, Brose N, Herzog E (2014) Proteomic screening of glutamatergic mouse brain synaptosomes isolated by fluorescence activated sorting. EMBO J 33:157-170

Boda B, Dubos A, Muller D (2010) Signaling mechanisms regulating synapse formation and function in mental retardation. Curr Opin Neurobiol 20:519-527

Chubykin AA, Atasoy D, Etherton MR, Brose N, Kavalali ET, Gibson JR, Sudhof TC (2007) Activity-dependent validation of excitatory versus inhibitory synapses by neuroligin- 1 versus neuroligin-2. Neuron 54:919-931

Foldy C, Darmanis S, Aoto J, Malenka RC, Quake SR, Sudhof TC (2016) Single-cell RNAseq reveals cell adhesion molecule profiles in electrophysiologically defined neurons. Proc Natl Acad Sci USA 113:E5222-5231

Frese CK, Mikhaylova M, Stucchi R, Gautier V, Liu Q Mohammed S, Heck AJR, Altelaar AFM, Hoogenraad CC (2017) Quantitative map of proteome dynamics during neuronal differentiation. Cell Rep 18:1527-1542

Graf ER, Zhang X, Jin SX, Linhoff MW, Craig AM (2004) Neurexins induce differentiation of GABA and glutamate postsynaptic specializations via neuroligins. Cell 119:1013-1026

Harris KM, Weinberg RJ (2012) Ultrastructure of synapses in the mammalian brain. Cold Spring Harbor Perspect Biol 4:a005587

Jiang W, Wei M, Liu M, Pan Y, Cao D, Yang X, Zhang C (2017) Identification of protein tyrosine phosphatase receptor type 0 (PTPRO) as a synaptic adhesion molecule that promotes synapse formation. J Neurosci 37:9828-9843
Kayser MS, McClelland AC, Hughes EG, Dalva MB (2006) Intracellular and trans-synaptic regulation of glutamatergic synaptogenesis by EphB receptors. J Neurosci 26:12152-12164

Kim S, Burette A, Chung HS, Kwon SK, Woo J, Lee HW, Kim K, Kim H, Weinberg RJ, Kim E (2006) NGL family PSD-95-interacting adhesion molecules regulate excitatory synapse formation. Nat Neurosci 9:1294-1301

Linhoff MW, Lauren J, Cassidy RM, Dobie FA, Takahashi H, Nygaard HB, Airaksinen MS, Strittmatter SM, Craig AM (2009) An unbiased expression screen for synaptogenic proteins identifies the LRRTM protein family as synaptic organizers. Neuron 61:734-749

McAllister AK (2007) Dynamic aspects of CNS synapse formation. Annu Rev Neurosci 30:425-450

Missler M, Zhang W, Rohlmann A, Kattenstroth G, Hammer RE, Gottmann K, Sudhof TC (2003) Alpha-neurexins couple $\mathrm{Ca}^{2+}$ channels to synaptic vesicle exocytosis. Nature 423:939-948

Pereda AE (2014) Electrical synapses and their functional interactions with chemical synapses. Nat Rev Neurosci 15:250-263

Sanes JR, Yamagata M (2009) Many paths to synaptic specificity. Annu Rev Cell Dev Biol 25:161-195

Sudhof TC (2004) The synaptic vesicle cycle. Annu Rev Neurosci 27:509-547

Sudhof TC (2008) Neuroligins and neurexins link synaptic function to cognitive disease. Nature 455:903-911

Sudhof TC, Malenka RC (2008) Understanding synapses: past, present, and future. Neuron 60:469-476

Varoqueaux F, Aramuni G, Rawson RL, Mohrmann R, Missler M, Gottmann K, Zhang W, Sudhof TC, Brose N (2006) Neuroligins determine synapse maturation and function. Neuron 51:741-754

Yang X, Hou D, Jiang W, Zhang C (2014) Intercellular proteinprotein interactions at synapses. Protein Cell 5:420-444

Zhang C, Milunsky JM, Newton S, Ko J, Zhao G, Maher TA, TagerFlusberg H, Bolliger MF, Carter AS, Boucard AA, Powell CM, Sudhof TC (2009) A neuroligin-4 missense mutation associated with autism impairs neuroligin-4 folding and endoplasmic reticulum export. J Neurosci 29:10843-10854 